\title{
Reimagining the Convoluted Plights of Refugee, Immigrant and Undocumented Immigrant Women: Implications for the Reauthorizations of the Violence Against Women's Act of 1994 in the United States
}

\author{
Buster C. Ogbuagu \\ College of Arts \& Sciences, University of St. Francis, Joliet, Illinois, USA \\ Email: bogbuagu@stfrancis.edu
}

Received: 21 August 2020; Revised: 24 November 2020; Accepted: 26 November 2020

\begin{abstract}
Background: Violence against women exists, is entrenched and shares commonalities among all cultures and societies, regardless of their level of civilization or the lack thereof. This act, which in some societies has now been recognized, therefore currently perceived, defined and interrogated as socially problematic is committed mostly by men, especially intimate partners and significant others, regardless of demography. Violence Against Women as an aberrant type of relationship interaction exists as a phenomenon that has largely been socially constructed, perpetrated, sustained and reproduced mostly by men. Although, and as a gender discourse, all women are recipients or potential recipients of violence perpetrated predominantly by men, however, new immigrant and refugee women remain at the apex as recipients of all sorts of violence, especially Intimate Partner Violence (IPV). Method: This study applied phenomenological interviews to explore how violence, particularly IPV against refugee women, including how the risk and propensities are further heightened and complicated by subjectivity labels. These labels include gender, race, socioeconomic, including undocumented immigrant status and language in host countries and continents, such as the United States, Canada and Europe. Results: The study found that IPV has serious ramifications for the physical and mental health of all affected women and their children, but presents a specially complicated problem for refugee and undocumented immigrant women as they strive to adapt to their host countries and environments. The study further evaluated new and existing policies, including the Violence Against Women Act of 1994 and its various reauthorizations, as well as evidence-based modalities that attempt to interrogate and attenuate this aberrant interactional process. Conclusion/Recommendations: It also explored policy recommendations that can be engaged in the sustainable protection of women, already victims of violence and those at high risk, but especially new immigrant, refugee and undocumented immigrant women, who have been socially, economically, culturally and linguistically deracinated by migration and refugee creating events.
\end{abstract}

Keywords: violence against women, refugee women, gender, immigrant, undocumented immigrant status, immigration laws, language barriers

Copyright (C2020 Buster C. Ogbuagu

DOI: https://doi.org/10.37256/ser.222021601

This is an open-access article distributed under a CC BY license

(Creative Commons Attribution 4.0 International License)

https://creativecommons.org/licenses/by/4.0/ 


\section{Introduction}

For as long as anyone cares to remember, women have borne the brunt of the vagaries of a patriarchal society, as chattel (Jones, 2012; Wenger, 1992) and non-persons in all cultures and civilizations (Kuerstein, 2003; Gaspar, 1996). At different points in history, women had no power, no rights, including those of life and limb and were at the mercy of males (they still are), as spouses and significant other (Mackinnon, 2006). Women, since the beginning of time have faced many, often socially constructed barriers to their health and development. These barriers, owing to the discourses of gender that are largely promoted, sustained and reproduced by men, have fringed women, as well as promoted a decline in their social mobility and life outcomes. In the worst case, the construction of gender and patriarchy gave birth and impetus to the use of force and violence by men to bring women in compliance, often wives (partners) and daughters for real or perceived recalcitrance (Tong, 1989). Tong surmises:

In the early nineteenth-century America, for example, a man was legally permitted to chastise his wife, without subjecting himself to vexatious prosecution for assault or battery, resulting in the mutual discredit and shame of all parties concerned. The rule was derived from English common law, which not only permitted husbands to beat their wayward wives, but instructed wives to kiss the rod that beat them (p.127).

For many centuries, most cultures, including those that have been adjudged as advanced, paid little attention to family and intimate partner violence, especially on the assumption that it was a family matter (Alaggia et al., 2009; Easteal, 1994). This was prior to their cognizance that family and intimate partner violence somehow found ways to trickle out into the community, contingent on several variables. Some of variables included those that border on society's obligation to apply their collective resources-hospitals, clinics, counselors and support system, etc. to nurse the victim back to health, until the next time that the violence as a cyclical entity repeats itself.

The issue of domestic violence has now found currency around the world, and increasingly problematized as a social malaise needing remediation (Easteal, 1994). The problem of family violence and its significance on the family and human systems, forced human rights groups to spring up and make demands on governments and nation states to take action to ebb its vicious tide. As a domino effect, the United Nations Convention on the Rights of the Child declared in 1989 that all children and minors, regardless of race, gender or location should have the privilege of equal protection from "physical or mental violence, injury or abuse, neglect or negligent treatment, maltreatment or exploitation, including sexual abuse, while in the care of parent(s), legal guardian(s) or any other person who has the care of the child" (Levesque, as cited in Barnett et al., 2011, p.8). In the case of Intimate Partner Violence involving women especially, the United Nations Declaration on the Elimination of Violence Against Women (1993) made a strongly worded statement that explicitly condemns the act as:

Any act of gender-based violence that results in, or is likely to result in, physical, sexual, or psychological

harm or suffering to women, including threats of such acts, coercion or arbitrary deprivation of liberty,

whether occurring in public or private life (p.8).

Although women continue to be short-changed by a patriarchal world and discourse across the board (Alaggia et al., 2009; Easteal, 1994), some suffer more than others, as in the case of refugee and immigrant women. If women, who are bonafide residents (have not been forced to flee by refugee producing events), citizens, preferred (dominant) culture and social class, find the issue of IPV cruel and unpalatable, imagine how unfathomably painful the discourse of IPV would present to a refugee or an undocumented immigrant woman.

A sincere understanding of the ramifications of IPV for a refugee, immigrant and displaced woman can only be arrived at by the exploration of the variables of gender, race, status, including residency (documented and undocumented) and socioeconomic class, as well as language. IPV as a single variable that creates discomfiture in women's life is life changing at best. However, at the worst, the entry of the variables of gender, race, immigration status-documented, but especially undocumented, socioeconomic and language status, create multi discomfitures for the refugee woman. In light of this finding, this study is not just about women and their tribulations that are derivatives of power, patriarchy, family and intimate partner violence, for much have and continue to be written about it. It is about constructing a framework for articulating, interrogating and sustainably dismantling the aforementioned subjectivity labels-gender, refugee, undocumented, displaced, socially and culturally deracinated, language barriers and other issues, which in concert promote, heighten and sustain the risk, incidence and reproduction of violence against refugee women. sustainable policy recommendations are also proffered to expeditiously end or at the least, attenute the tide of Intimate Partner Violence, especially those perpetrated against refugee, immigrant and undocumented immigrant women in the 
United States and across the globe.

\section{Literature review}

Globally, women, whether they are citizens, immigrants or refugees are by default, targets for intimate partner violence, including sexual abuse. Refugee Women's Alliance-ReWa (n.d.), posits that these violence vulnerabilities are further exacerbated by relocation to new and strange spaces (Alaggia et al., 2009). Here, and especially in the case of refugee women, they endure barriers to seeking assistance due to unfamiliarity with language (Alaggia \& Maiter, 2006), lack of economic prowess, social and community isolation and alienation. Others are their inability to access services (Sokoloff \& Dupont, 2005), the convoluted nature of the legal systems, their undocumented immigration status, as well as the laws governing Intimate partner violence, where such exists.

As a social aberration without an end date, intimate partners are the leading sources of forcible rape of American women. Bachman (2000) argues that in the United States of America, for instance, it is often not the stranger, as it is a woman's intimate partner that is implicated in forcible rape and sodomy of such women. To buttress this argument, reports from the FBI Uniform Crime statistics (Cooper \& Smith, 2011) highlights that 9.7 percent of homicides by an intimate partner account for all murders in the United States. These murders are categorized under three major groupsan abusive husband or spouse kills his wife; an abusive husband is murdered by his wife, while defending herself from an abusive husband; and in very rare cases, an abusive wife kills her husband (Straus, 2005). To show the extent and pervasiveness of intimate partner violence, the United States Department of Justice supplied that in 2001 (Rennison, 2003) over half a million women have been victims of violence in the hands of their partner. Fortunately, it is a figure that has fallen by over six hundred thousand from that of 1993. This is thanks in large part to the enactment of the Violence Against Women protocol in the United States (Violence Against Women Office, 2000, 2005), prior to which 1.1 million women were victims of IPV. It is our assumption that these statistics concern women citizens in the United States, some of whom have the audacity of citizenship to report it. However, it also highly feasible that a large number of immigrant and refugee women fall into this cohort, but for obvious reasons, including their undocumented status, (Morash et al., 2007; Shirwadkar, 2004), these may not have the capacity to report it or pursue criminal charges against their assailants.

The poignancy of IPV is demonstrated by a finding by Hemenway et al., (2002) that American women comprise only thirty-two percent of women within the twenty-five high-income societies. Paradoxically, US female homicide rate represents 70 percent of all murders, totaling about 4,000 each year. Of these femicides, eighty percent was by firearms. A comparative analysis by Hemenway, Shinoda-Tagawa and Miller further reveals that more than Canadian women, American women were three times more likely to be murdered. Juxtaposed with the United Kingdom, US women are eight times more likely to be victims of homicide and IPV. Rand (1997) buttressed this finding by highlighting statistics compiled by the US Department of Justice, on violence-related injuries addressed in hospital emergency rooms. In this, Rand found that male spouses, a boyfriend, or an ex-male spouse owned culpability in thirty-seven percent of grievous bodily injury endured by a woman. For Yllo (2005), in order to articulate domestic violence and IPV, especially those against women, we have to first explore its intersectionality with gender and power. With the United States leading in violence due, to the large number of guns and other weapons (Felson, 2002) at its disposal, women throughout the globe are frequently targeted for violence, estimated at half a million between 1976 and 2000. In the case of premature deaths of women by IPV, it is the seventh source of such death in the United States (Greenfeld et al., 1998). Of these, African American women aged between 15 and 45 are prematurely deceased by gun-related IPV. Several theories underpin IPV as the next segment of this research shows.

\section{Theoretical framework}

Intimate partner and family violence theories have assumptions in-grained in them, because they are only assumptions, which are products of social and cultural constructions, as argued by Ogbuagu (2012). Ogbuagu further posits that the intricacy and convoluted nature of violence in general, but particularly family violence has left researchers scratching their heads in bewilderment. This is contingent on previously held assumptions (Barnett et al., 2011) that it 
goes against the grain for one who professes to love and protect at one stage, doubles up as violence and harm agency in another instance. The application of macro theory that utilizes a broad spectrum of variables or factors comes in handy, if we are to attempt a reconnaissance of the family and Intimate Partner Violence as a phenomenon. This large number of theories have been advanced for the often intractable degree of IPV that women universally have endured in the hands of their male spouses. The jury is still out and may be out for a while in its evaluation of these theories. This arsenal of theoretical conjectures is beyond the scope of this research, which leaves us enunciating just a few, rather pertinent ones as a fulcrum for lounging in this study. They include patriarchy, cultural and broad socialization factors, social acceptance and acquiescence of family violence, feminist theories, social-structural variables as theory, deterrence theory-the low-cost of family violence and punishment (Barnet et al., 2011; Kallivayali, 2010; Bhuyan et al., 2005; Jacobson \& Gottman, 1998; Dutton, 1998; McCall \& Shields, 1986; Dobash \& Dobash, 1977). Come along as we explore some of these variables that promote and sustain violence against women, beginning with patriarchy.

\subsection{Patriarchy}

The practice of Patriarchy is contingent on an unearned but acquired privilege that men have been assigned or arrogated to themselves as controllers and dominators of women, just because of their masculinity and the latter, femininity (Gangoli, 2017). The discourse of patriarchy is further strengthened in favor of men as a sociocultural order that is covertly, often, overtly embedded in the marital contract, including role assignment (Durkheim, 1893/1947). According to Ogbuagu (2012), it represents "an assumed privilege assigned to men to control and dominate women, solely predicated upon the former's masculinity" (p.6). To this extent, patriarchy was constructed by men, and for their benefit only. Contingently, patriarchy rests perpetually and is deliberately inserted in the interactional process, and reproduced by those men, who cite the Judeo-Christian Bible as their source of authority over women. To fight centuries old patriarchy in the hope of gaining some concessions, women and advocates began to engage in feminism and feminist movements, which continue to this day.

On the issue of gender, gender identity and gender inequality, Ridgeway and Corrells (2004) have observed and acknowledged a paradigm shift or even revolution in society's theoretical conceptualization of the real definition of gender. For them, this theoretical conceptualization is not only a social phenomenon, but more poignantly, one that is also socially constructed-by men especially in the socialization process. However, this aberrant socialization process did not end in the family systems. It cankerwormed itself into the public arena, therefore institutionalized system of social practices. These systemic social practices ascertained that there will always be and impenetrably, two different but significant categories, comprising women and men, but not necessarily in the same order. This organization of social relations and order creates abyssal differences at all levels of society that emasculate women in the final analysis.

\subsection{Cultural and broad socialization factors}

This theory argues that since culture is responsible for constructing patriarchy and its appurtenances of power, which uses violence as a vehicle to gain power and control, it therefore condones family violence (Barnett et al., 2011). Those who practice and become witnesses to violence, be they in sports, films or culture, become socialized into it from infancy. They then proceed to normalize these behaviors, expressing or externalizing them in their activities of daily living, frequently against women. In the case of the United States and its counterparts having a monopoly of violence, for instance, this theory assumes that family and intimate partner violence is a part of normal relationships, sewn into the socialization fabrics.

Ridgeway (2014) in furthering the gender postulates of Ridgeway and Corrells (2004) inserts the concept of status in the gender emasculation repertoire and ensuing gender discoursal matrix. Ridgway (2014) is vehement that the concept of status, with its ubiquitous accoutrements of power and control has serious ramifications for the denigration and subordination of the "others" including gendered entities. She argues that status is an ancient and universal derivative of inequality, which not only awards esteem and honor, but also is reproduced within contemporary institutions and organizations that are highly hierarchized. Further to this, is the argument by Ridgway that status, of which women are forcibly ensconced at its lowest totem pole are socially and culturally constructed, therefore designed to streamline human relations and interactions. She finds that the concept of status has two dimensions, which manifest themselves at the macro levels of societal abstractions. The first dimension consists of deeply learned, deeply 
internalized and highly reproducible normative understanding of status allocation, which is frequently covert. The second summation by Ridgeway is predicated on other more overt set of variables and frequently changing common knowledge status beliefs. It is from these common knowledge status beliefs that those who gained its scholarship following a prolonged tutelage are able to coordinate activities, but especially pass judgements about who does or does not deserve a higher status. In this dispensation and since only men have wrested this power to maximize individual outcomes, the same men use such maximized individual outcomes to better their gender, always at the expense of women.

Opines Ridgway, status as a concept has deep rooted entrenchment at the micro-level, which eventually seeps through into the macro-level, benefitting those members occupying higher status echelons, while throwing wrenches into the wheels of mobility of lower status members. Thus status beliefs skew the evaluations of competence and suitability for social mobility in the authority arena and interactional preferences. When these status beliefs become internalized, entrenched and reproduced, those who are its prime beneficiaries, therefore gatekeepers put up resistance to challenges for equality posed by those considered to be lower-status group members. In this dispensation, "Status" as concept is utilized by non-gendered entities, usually men as a central tool that fabricates durable patterns of inequality that is solely based on gender differences.

\subsection{Social acceptance and acquiescence of family violence}

This theory amplifies the stranglehold of patriarchy, which in turn borrows from "an ecclesiastical moral obligation to eschew sparing the rod in order not to spoil the child" (p.6). (Jones, 2012; Mackinnon, 2006; Wenger, 1992; Womensafe, n.d.). Stedman (1917) highlights the concept of "Domestic Chastisement" used by men and as a historically watered-down instance of violence that a man perpetrates against his wife when the latter physically hits (assaults) her. Here again, we explore the teachings of the Bible and other holy books, some of which are alleged, better still, have been hijacked for their own purposes by especially male proselytizers of the various religions. These use the holy books to prod those in authority, especially parents and caregivers to use force, including physical force to engender compliance. Historically, in the United States and some other parts of the so-called Third World, women as the property of men are required to be physically disciplined by their spouses for perceived recalcitrance (Mackinnon, 2006; Pan et al., 2006; Bhuyan et al., 2005; Tong, 1989; Womensafe, n.d.). How do Feminist theories view IPV?

\subsection{Feminist theories}

The Feminist theories, according to Barnett et al. (2011) explore four intersectional variables implicated in gender and power relationships and how this power is utilized by men or other humans to engage in, promote and sustain IPV. These four intersectional variables include: the historical importance that society places on the family as a social institution; the urgent need to promote women's safety by first, understanding their lived experiences and second, validating these lived experiences; and finally, and in order to appropriately assist women, engage in and apply a sincerely sustained research and theorization about family violence.

\subsection{Social-structural variables as theory}

This theory, among other variables finds support in the works of Ridgeway (2014); Sokoloff \& Dupont (2005); Ridgeway \& Correll (2004). All the authors explore the socially constructed variables of "minority" "gender" and "lowincome status" to understand and explicate their nexus and complicity in family violence and its sustained practice. The scope of this study precludes an in-depth analysis of this theory as we explore the Deterrence theories.

\subsection{Deterrence theory-the low-cost of family violence to its perpetrators}

Disciples of this postulate (Barnett et al., 2011) interrogate the utilization by the justice system of the ever faulty, but frequently used concept of punishment, rather than restitution in its bid to stem family and Intimate Partner Violence. It posits that woman abuse and IPV happen and are reproduced because the legal and judicial systems fail women by refusing or neglecting to adequately hold male perpetrators fully accountable for dehumanizing women 
(Nayak et al., 2003). Even at that, Punishment as an agency of deterrence has been applied so feebly and lackadaisically that perpetrators as its primary recipients have learned to discount its weak deterrent properties. This downgrade by perpetrators, then promotes, reproduces and perpetuates the same family violence, which ab initio was the raison d'etre for the concept of "Punishment". Advocates argue that since the punishment is frequently lower than the crime committed, there therefore is no serious incentive to cease and desist from the behavior that hurts vulnerable others, including, but especially women.

\subsection{Punishment}

The Punishment theory is predicated on the parents and caregivers as agents of socialization, including punishment for recalcitrance. It argues that these parents and caregivers have it as their primary responsibility to hold their charges accountable for recalcitrance and bad behavior, which frequently utilizes "Punishment" as its deterrence agency (Nayak et al., 2003). To this extent, the punishment theory is in the same continuum as the deterrence theory, in that it assigns the role of meting out immediate and just retribution on their children and charges for anomalous behavior. If this is the case, "Punishment" for the purposes of eliciting amenability to good behavior by children and adult alike falls flat on its face. Why so? When we control for the fact that crime and bad behavior persist, despite sometimes stringent punishment regimen by the family socialization agents and the society, then questioning the efficacy of "Punishment" as an agency of deterrence becomes fait accompli (Barnett et al., 2011).

\section{Methodology}

This qualitative and ethnographic study utilized the phenomenological theories or approaches, of which interviews stand as the primary source of eliciting the lived experiences of its participants. Espoused by Husserl (1962-Translated by W.R. Boyce Gibson), phenomenology encourages the investigator of a phenomenon to reduce the natural world to its pure state or consciousness. Husserl eschews scientific rationality, which he flays for its aim is to reduce humans to worldly objects. Husserl and later, Merleau-Ponty (1942) stress that scientism and its reductionism properties seeks out objects, such as biology, physics, chemistry, etc. that it can render completely amenable to exhaustive rationalization, eventually leaving these without "soul" (emphasis added). Having relegated scientism to the back burner, the researcher is to see what is then left as a pure framework to work with to understand the phenomenon (Moran, 2000; Sokolowski, 2000; Hammond et al., 1991). Husserl also goads for bracketing, in order to free ourselves from prejudices (of the natural, disemboweled sciences) and instead, anchor ourselves as pure observers, who are seeing the phenomenon divorced from any prejudices and presuppositions. For Husserl (1962-Translated by W.R. Boyce Gibson), phenomenology is a descriptive, detached (from natural sciences especially) analysis of consciousness, in which objects and their correlates are comprised or constituted. Merleau-Ponty (1942) agrees, adding that whatever we claim as our knowledge of the world, including the so-called scientific knowledge are all derived from a first-person perspective or experiential narrative (phenomenology). For Merleau-Ponty, without experiential narrative or a first-person perspective, science as we have come to know it would be bunkum. To this extent, the study used phenomenology to "listen" to the lived experience narratives of the participants-telling their own story about themselves.

\subsection{Participants composition}

The study participants is an admixture of 97 new immigrant women, refugees and undocumented immigrant women residing in some large cities of the United States and Canada. Most of the women arrived in one of the two countries from several troubled regions of the world, including Afghanistan, Iraq, the Tamil of Sri Lanka, West African nations of Nigeria, Ghana, Sierra Leone and Liberia. Others are from the Central African Republics of Rwanda, Burundi and the Congos. There were also female participants from Indonesia, India, Pakistan and China. Of the 97 participants, 38 participants or 39 percent stated that they were still married to their spouses; another 43 participants or 44 percent of the women stated that they were separated or divorced from their spouses on account of IPV, but maintained some form of relationship with him, leading to their IPV experience. The rest 14 participants or 14 percent stated that they had ex-boyfriends, who were responsible for their experiences with IPV. The ages of the participants were from 26-58. 
Additionally, all the participants admitted to having a religious belief or affiliations as Muslim, Christian, Buddhist or other, including Animism.

Most of the participants were located and accessed through the researcher's involvement with cultural communities in the United States and Canada over a 7-year period, longer for Canada. All were introduced by mainly female acquaintances and advocates within the cultural and immigrant communities. These had brought the participants to cultural events as a means of ending their isolation, or finding resources to address their experiences with IPV. When sufficient trust had been established, and for some, for obvious reasons, this took a while, the participants eagerly volunteered other women experiencing the same phenomenon. 60 participants or 62 percent of the interviews were faceto-face and the balance of 37 participants or 38 percent was by telephone.

I am allophone, which means that my mother tongue is neither English nor French. However, I do speak English (including its Pidgin variant), French and Igbo, therefore was able to conduct many of the interviews in one of these media. For the other participants, who did not speak English or spoke variants of hard-to-comprehend English and other languages, I elicited the assistance of translators in those languages to assist in the navigation of the interviews. In most cases, the participants themselves, who were aware of my inability to speak their language were extremely kind enough and invited their support persons, who doubled as translators to the interviews. All face-to-face interviews were tape recorded, while those by telephone comprised mainly field notes, which were transcribed after the fact. Prior to the interviews, the investigator also mailed or and distributed an Informed Consent form to each participant, which they perused and signed as their agreement to participate in the inquiry. In addition to the signed Informed Consent forms, I also sought and received verbal consents by the participants, which were audio recorded whenever they used a translator or one was needed for the interviews. Additionally, and as a social worker, a social work practitioner and especially one that is bound by the National Association of Social Workers-NASW Code of Ethics, I therefore professionally understand the issues of patriarchy, gender/feminist theories and the intersectionalities of oppression, especially against women. I also understand my position of power, first as male and as a so-called purveyor of knowledge, therefore immense power, including those that can oppress, either by commission or omission. Consequently, I strove to format my interviews and interview questions that I posed to these already vulnerable women of IPV in ways that I hoped did not multiply gender oppression.

\subsection{Emergent themes}

Emergent themes from the interviews and discussions included the issues of patriarchy-including culture, migration patterns, integration and adaptation issues, feminism, domestic disturbance protocols, cultural expectations, and marriage patterns, especially those outside of age cohort. The others were the extended family system, diasporic financial expectations, isolation, obligations and burdens, their concepts, but especially perceptions of "help" in North American societies. The issue of Intimate Partner Victimization, the immigration statuses, language, language barriers, the ethnocultural abhorrence of exposing private family issues to the public and strangers also emerged from the interviews of the refugee and immigrant women. I have tried below to address some of the emergent themes in the discussion section.

\section{Discussion}

\subsection{Refugee status: All refugees-"normal" integration and adaptation issues}

According to the Center for Disease Control (CDC) (2013), the world sends approximately five hundred and fifty thousand immigrants to the United States, of which fifty thousand are refugees. The United Nations 1951 Geneva Conventions Declaration on Refugees is clear because most of these refugees are unable, sometimes, never able to return to their homes and normal places of domicile for fear of persecution and danger to life and limb. As inviting as the need to assure safety by fleeing to a place of refuge presents, the CDC maintains that their odds of resettlement and integration into the new host societies are myriad, sometimes insurmountable. Indeed, those who are in temporary locations, where their needs cannot be met may be considered for a third country. In this light, and according to the $\mathrm{CDC}$, of the ten million refugees in different parts of the globe, only about 1 percent has any chance of being relocated to a safe third country. This leads to the exploration of the peculiar integration and adaptation issues facing refugee 
women.

\subsection{Refugee women's peculiar integration and adaptation issues}

United States Census Bureau (2008) suggests that approximately 18 million women and girls have left from many countries all over the globe. The fact of gender (Jones, 2012) more than any other demographic variable, leaves these immigrant and refugee women as a high at-risk population. Women, particularly face a perilous immigrant and refugee journey as they are singled out for rape, sodomy and sex trafficking, as Jones continues. As a social category that is highly diverse, these immigrant women left under a myriad of events, therefore have a multiplicity of immigration statuses. As a social category, they are highly diverse in their sociocultural, religious (see methodology section), economic and other background, as well as diverse in age (see methodology section), levels of education, acculturation, sexual orientation, and marital status, among other several variables. Contingent on their collective identity as immigrants (documented or irregularized) or refugees, they share lived experiences (Moran, 2000), everyday realities and other subjectivities appertaining to their designation. This designation sets them apart from other women from the host society's mainstream. This plethora of similarities and differences, saddle providers of services with many challenges, especially with regard to culturally competent services that promote survivability of domestic and intimate partner violence. We shall deal with this later in the study.

Whereas extensive research has been conducted on the issue of domestic violence among the majority populations in Europe and the Americas, little has been done on immigrant communities, due to their fringe status in the respective societies. According to Yoshihama (2008), even the little research done on this population are fraught with methodological hamstrings or errors, which have helped little in the resolution of IPV in this population. Some of the methodological limitations include exclusion, the wanton use of aggregation, over emphasis of a sociocultural group to the detriment of others, limited attention to socio-cultural context and insufficient comparability. The scope of this study precludes an in-depth analysis, but I shall attempt to succinctly enunciate these variables.

\subsection{Exclusion}

Language and cultural barriers have meant that researchers and investigators having limited or no knowledge of a particular cultural community, have avoided investigations in those communities (Yoshihama, 2008).

\subsection{Wanton application of aggregates}

Within-group variations are frequently ignored or glossed over, due to the wanton aggregation of sub-groups of immigrant populations. The fall-out is that within-group variations are frequently unidentified or missed.

\subsection{Over emphasis of a sociocultural group}

The proximity and contiguity of Central and South America to the United States has created an overemphasis on Hispanic and Latino experiences. This situation concomitantly limits attention to other equally important communities of African, Arab and European (especially Eastern European) origins.

\subsection{Limited attention to socio-cultural context}

Mainstream or majority populations provide the so-called standardized measurement instruments, which are erroneously applied as generalizations to other immigrant populations. The fact remains that no group is monolithic, as there are variations or sub-group and categories existing even within a group. Therefore, the application of majorityoriented or purposed instruments to measure these within-groups or those outside of it will ultimately produce flawed outcomes. Why? The experiences of majority populations may be entirely lacking or dissimilar with those of minority populations (Yoshihama, 2008). 


\subsection{Insufficient comparability}

There exists a myriad of studies, be they quantitative or qualitative methodologies, having an array of sampling methods, including data collection techniques and other research methods. The use of the different research methods, invariably produce different and sometimes, conflicting outcomes that disallow or provide limited comparability of findings among studies (Yoshihama, 2008). Both quantitative and qualitative methodologies utilize limited samples of specific immigrant groups, which they apply in situating the other groups within their socioculturally-generated violent environment. This is so and frequently occurs, even when some of these immigrant groups implicated in the generalized outcomes are nowhere near the studies and did not participate.

There is a finding that IPV occurrences are limited in refugee and immigrant populations, when juxtaposed with such occurrences among the dominant populations, citizens and other groups. However, the fact that this cohort is a refugee and immigrant population, creates many variables that preclude the victim's ability to seek help and redress (Alaggia et al., 2009; Latta \& Goodman, 2005; Asylum Aid, 2003). Consequently, the IPV outcomes, when they occur, are frequently more severe, often prolonged and sometimes intractable and must be addressed for the sustenance of a healthy community (Rana \& Marin, 2012; Robert Wood Johnson Foundation, 2009). I shall attempt in the following discussion to enunciate some of the more relevant preclusionary variables common amongst refugee and immigrant women, when compared with IPV victims in their normal places of domicile. My argument begins with the question about why refugee and immigrant women fall through the cracks and into IPV. Some of these reasons begin with the issue of culturally relevant programs that are largely absent or of little value to the immigrant (including the undocumented) and refugee woman IPV victim.

\section{Why do refugee and immigrant women fall through the cracks of IPV? 6.1 Dearth of culturally (competent) appropriate personnel/programs in host society}

Immigrant and refugee women have little and sometimes just the blouses on their backs when they arrive in their host countries. It is a double jeopardy, when they also become victims of domestic violence. 62 participants or 64 percent of the women in this study, especially those from Central African nations of Rwanda, Burundi and The Congos share the same experience, on account of their experiences with civil wars and unrests. In light of this, Rothman (2008) argues that in order to provide a culturally competent domestic violence services to immigrant and refugee women, practitioners have to engage in an in-depth and comprehensive articulation of the nuances of domestic violence within cultural communities (Kallivayalil, 2010; Dutton et al., 2000). To achieve this, Rothman (2008) (see also National Association of Social Workers National Committee on Racial and Ethnic Diversity, 2001), proffered a definition of cultural competence. They see it as a process whereby systems and individual practitioners respond, recognize and become adeptly sensitive to their clients' cultural encumbrances. These include recognizing, valuing and respecting clients' cultures, languages, races and ethnic background. Cultural competency also includes the understanding of the interplay of class, religion and any diversity issues and encumbrances that this client has been socialized into and values, whether or not these are meaningful to the practitioner. 22 women or 23 percent of the participants were Muslim, while 8 women or 8 percent declared Animism (ancestral worship) as their religion. As a further guide, practitioners, systems and service providers must make an effort to acquire knowledge about the cultural, political, religious and socioeconomic matrix, which contribute to the immigrant woman's experience with domestic and intimate partner violence.

Immigrant and refugee women, for the fact that they are labeled as such, have been socially and culturally deracinated. This means that they have lost their everyday normal and cultural ways of doing things (Bauer et al., 2000). 78 participants or 80 percent of the women participants did not have other family members in North America, except their spouse, who is now the abuser and main stressor. Host societies only offer such programs that are consistent with their normative ways of doing things, as well as programs that they may erroneously believe may serve the best interests of the refugee woman, which may not. The actual fact is that the programs may harm or just be ineffective, because they are maladaptive or injudiciously transplanted. Intimate Partner abusers also invoke the immigration status of their victims in the abuse. 


\subsection{Abusers piggyback on immigration status of refugee and immigrant women}

One of the more serious issues affecting immigrant and refugee women is their status in the host country. Whereas many may be undocumented, others have immigration statuses that are on a shaky ground at best (Alaggia et al., 2009). At the worst, these women were sponsored by their spouses or paramours, who now use their power as sponsors to abuse the women (Ingram et al., 2010). In most cases, the abusers have the threat of deportation hanging like the sword of Damocles hanging over the hapless woman's head. In this vein, 83 women, representing approximately 85 percent of the 97 respondents declared that they were sponsored by their spouses (husbands), who now threaten to deport them. Only 14 women or the equivalent of 14 percent of the respondents were not married to their sponsors per se, and admitted to be paramours or had a not-too-discernible spousal relationship with their abuser.

Although, in most cases, the abusive spouses have no power or capacity to effect the deportations of their spouses, the new immigrant victim does not know this. These women may be illiterate, as shown by 55 women or the equivalent of 57 percent of the respondents, who barely made it to junior high, uninformed or completely isolated-78 participants or 80 percent of the respondents, by their abusive spouses. The findings by the study that the fleeting immigration statuses of the women placed them at a higher risk for experiencing Intimate Partner Violence are consistent with the comments made by the women, many of whom I spoke with through an interpreter. In addition to using informed consents, written and verbal, especially in the case of the use of translators, I have used pseudonyms to protect the confidentiality and identity of the participants in this study. There were 97 female participants for this study, which makes the verbatim inclusion of all the participants' voices (in the form of direct quotes) infeasible. On account of this, I have included a few verbatim (voices) of my interviews with some of the women in the study as enunciated by the following excerpts.

Investigator: Madam Ngozi, (Madam Ngozi speaks acceptable English although she came with an interpreter and support-a woman) could you please share your story about your experience with your family since you arrived in the United State?

Ngozi: My husband married me when I was very young. I knew nothing about the world. It was an arranged marriage, because he came to the village from America and came to my parents, who were excited about having a daughter married and living overseas. I arrived in the United States under my husband's visa...he applied for me. When I came here, he began beating me, saying I was not making enough money from my factory job, even though I gave him every penny that I was paid. I had no one. He did not want me to associate with anyone, including those from my country...it's hell and if I had known I would not have married him...(incoherent due to sobbing)...every time, when I tell him to stop, he said he is going to make sure that I was removed back to my country...I am afraid because I love him truly, truly and don't want to go back to my country... what will happen to my four children if he succeeds and I'm taken back to my country...? and I don't know what to do...I cry everyday... and he doesn't care if I live or die...I think he could kill me if he has his way and one day he will because he beats me whenever he likes and is cruel to me...what will happen to my children...?

Another immigrant woman from India, Sneha (name changed), provided a harrowing narrative of Intimate Partner Abuse, gleaned through an interpreter who spoke her language, Urdu.

Investigator: Nice to meet you, Sneha. What is going on with you, if I may ask, please?

Sneha: My husband Raj (pseudonym) married me as a child. It was an arranged marriage and my parents paid a lot of dowry on my head. Raj's parents live here in America and they married me and brought me to America and my trouble started right away...he controls everything. I don't know how to speak English so he takes advantage of me, including beating me and threatening to send me back home to India and demand his dowry back from my parents. He has a lot of money here and even my parents are afraid of him and my parents also say that I cannot return to India because I am already married to him and my family has been friends with Raj's family for a long time.

Investigator: Why would you or your parents for that matter be fearful of your husband?

Sneha: Growing up in India, I know that women do not have much say...I never thought that it would even be worse here in America... I do not work. How can I work in America if I can't speak English...so I depend on him for everything...I'm Kshatriya (warrior/ruling caste) in India but Raj has made me Dalit-(lower caste-formerly "Untouchables") in America..., she sobbed. I'm sure that if I were in India, he would have killed me or burned me alive by now... at least in America, they have good laws...

In some cases, the women are literate even in the language of the host country, as shown by 57 percent, who barely completed Junior high. However, they often refrain from advocating for themselves, due to the threats of physical 
violence against them. For this reason and as Robert Wood Johnson Foundation (2009) opined, "Homicides linked to intimate partner violence are higher among immigrant and refugee communities, perhaps due to an inadequate response by existing systems and institutions" (para.27). In other cases, the woman is unfamiliar with the social and cultural system in the host country, which plays a large part in their inability or unwillingness to access resources (Barr, 2009; Crandall et al., 2005). The next reason that refugee and immigrant women fall through the crack is language or the lack thereof.

\subsection{Language \& communication barriers}

Refugee and immigrant women come from all parts of the globe, some with languages other than English, German, French or any of the major languages often spoken in the industrialized world. Even when they belong to societies that speak any of these languages, they are often variant forms-pigeon, Creole, etc., which may be challenging to communicate with service providers in the host country. Look at it this way. The United States is a single country that has English as its lingua franca, yet some regions have variants of the language or speak with such accent that it may be challenging to decipher what is actually being uttered. Of the 97 women interviewed, 40 (out of the 55 women who barely made it to Junior high school) or 41 percent could not speak English in any form. 30 women or 31 percent of the respondents spoke a smattering of English, with heavy, sometimes hard-to-comprehend accents, having dialectical nuances. Only 27 participants or 28 percent could speak any comprehensible English. Of these, only 10 women or 10 percent spoke fluently, but with heavy accents.

I interviewed many of the women who spoke some English. However and on account of the scope of this research, only two of the interviews, therefore narratives, comprising respondents from Ghana-Adwoa and Sierra LeoneFatmata can be fitted into the section on language barriers that refugee and immigrant Intimate Partner Violence women experience. These IPV women in this section used and spoke variants of English that were extremely challenging to comprehend. The interviews were conducted by phone and both women who had stand-by translators, doubled as a support and chimed in when the communication became tough going.

Investigator: Hi Madam Adwoa, nice to meet you

Adwoa: Same here, how you do? Adwoa sighs and you could sense the grief and sadness in her voice

Investigator: I am doing well, thanks for asking. Do you mind, Madam Adwoa telling me what brought you to the United States?

Adwoa: My husband, Kofi came to the US many years ago and married Oburoni (meaning a Caucasoid or White(woman), then they divorced...I don't know why and he did not tell me. I am from Akan (one of Ghana's ethnic groups). So, he came to my village and said he want to marry me. "He old pass me"-(meaning he is much older than me); in fact his daughter is older than me. So he prepared the visa in America and I came to join him. He was treating me like his house maid, even sometimes like his slave... One day when he went to work, I called my parents in Ghana and told them that Kofi was mistreating me. They told me to be patient with him. My parents then told him to be nice to me, so he knew that I had told them and he seized my phone, my passport and disconnected the land line and seized all the little money I had... and then he began to beat me for any little thing... almost everyday. I did not know anyone and my English is not good enough to tell anyone what I was going through... I was afraid that they may not understand me, believe me or even laugh at me because my English is very bad... I found another way to call my parents in Ghana. They asked me what I was doing to offend him and I told them that I was not doing anything to offend him. So I kept quiet until I met my friend-she confirmed that the person with her during this call was that friend.

Fatmata, a Sierra Leone native has been living with her husband, Amadu since they arrived in Canada during that country's civil war and as a part of the privately sponsored refugee resettlement program. The issues with Fatamata's Intimate Partner Victimization are not so much the case of status than it is of language and fear of authority. During the Sierra Leonean Civil War, the concept of authority and power was utilized extensively to oppress (rape and sodomization) women (Human Rights Watch, 2003). On account of her lived experience, I ascertained that she knew who I was, what I did for a living, including that as a Social worker. I also clarified the Informed Consent process, which she read, agreed to and signed for the interview to proceed. The following are excerpts of my interview with Fatmata.

Investigator: Madam Fatmata, thank you for taking the time to meet with me for this interview.

Fatmata: Thank you. How are you?

I also expressed my gratitude to the woman, who accompanied as well as helped to translate and unknot some of 
the language barriers that existed between us

Investigator: I am well, thank you for asking. What is going on between you and your husband, if you don't mind me asking?

Fatmata: My husband Amadu (name has been changed to maintain confidentiality) came to Canada as a refugee from Sierra Leone. After he got his papers, he applied for me and I joined him here in Canada...for the first few months, everything was going very well and then the drinking started... and then the drugs...it was unbearable. I told him to stop so we can realize our dream of some peace in Canada and may be settle down. When he was drunk, he comes home and finds fault with everything... and then the beating and the put-downs. He called me all sorts of names...called me illiterate and said I was no use to him or anyone. Amadu has lived in Canada for a long time and he works and has money...but I have nothing except my children... I called the police a few times and they arrested him...but he is my husband and I love him and want him in my life... he was the one who brought me to Canada after all and I did not want to appear ungrateful to him... If I can go to school... maybe I can learn to speak English well or even French and then I can work and take care of my children without him. At this time, I am not sure that anyone will even understand what I'm trying to say... (I retorted that I did and she thanked me profusely.)

Investigator: Madam Fatmata, do you have any children and if so, where are they?

Fatmata: Yes, we have two children, a boy and a girl-10 and 8 years old and they are staying with me at a women's shelter until we can find permanent housing away from him. They were both born here... (gesturing towards to ground to mean Canada) when the drinking and beatings became unbearable, I just took my kids and left for a shelter. I'm tired of them watching me beat by him. Who knows if one day, he is going to start beating them too...I didn't want to wait for that day to come as I could see it coming... when he's drinking a lot and using drugs, who knows? It may be a matter of time before he turns on them too...I don't want them to think beating people is normal or they will beat their wife or allow their husband to beat them when they grow up and get married... I enrolled in an ESL but got pregnant and stopped...now I don't know what else to do and I don't have any money to take care of myself or my children...

From the foregoing (interviews), it is evident that on account of the existing language barriers, refugee and immigrant women, who are victims of IPV, have little or no way of communicating their discomfiture to the law enforcement agencies, assuming they had a regularized immigration status. These also are unable to engage in any meaningful communications with healthcare, wellness and other service providers. Some of the refugee women interviewed for this study stated that although they could speak a smattering of English (30 participants, who barely made it to Junior high), they were too embarrassed to speak for fear of ridicule (Bauer et al., 2000). They also feared discrimination on the part of the native service providers, some of whom they reported as insensitive. Worse still, the immigrant and refugee women, having been raised in patriarchal and oppressive societies, are fearful of authority figures in the west, who they fear could initiate deportation proceedings against them or successfully deport them on a whim. This sense of bewilderment is exacerbated by an especially new, often faceless social environment that they have suddenly been thrust into. Recall, that most of the refugee women, prior to migration, lived in close knit, cultural and sometimes, communal-consanguineal and endogamous conjugal societies, which experiences are now in dissonance with what obtains in the new, faceless and individualistic host societies. How and who defines what actually constitutes Intimate Partner Violence among cultural communities?

\subsection{Lack of consensus on the definition of IPV among cultural communities}

According to Kanuha (2006), definitions about what constitutes IPV vary by several demographic indices. These definitions are contingent on several variables, some of which include where the definer was born and raised, as well as the community they are domiciled in, including how that community defines and conceptualizes abuse or assault (Bhuyan et al., 2005; Crandall et al., 2005). Additionally, the variables of patriarchy and masculinity (Kanuha, 2006) provide platforms of unearned powers that obfuscate any meaningful definition of abuse or IPV. The more a community, especially the cultural type sees these variables as the norm, the more likelihood that it will fail to raise alarm, when violence against a woman occurs, simply because it does not perceive it as a problem (Pan et al., 2006). In these cultural communities, there is a lacking in identifying the nexus between a controlling behavior, even one that may result in some form of physical control, such as shoving and threatening. Here, and in some cases, community members may identify IPV, but label it as a private or family matter (Sorenson, 2006; Klein et al., 1997). 


\subsection{Apprehension over "washing the family and community's dirty linens in the public."}

Women, including refugee women as nurturers of their families and communities, are often faced with the dilemma of caring for and protecting themselves or caring for and protecting their family and community in a largely patriarchal society. Most women from cultural communities, engage in altruism on behalf of their families and communities each and every day, and have been known to go without so their families are better supplied (Bhuyan et al., 2005). In these, cultures, a complaining woman is at the least a disgrace to the family. It is worse, if they take their family and community matters, no matter how grave to outsiders for consumption or any reason for that matter. All 97 women participants in this study stated that they did not wish to disgrace the family and become the laughing stock in their home countries if they reported the abuse. They all stated that they were indebted to their abusive spouses for bringing them to North America, therefore did not wish to sound ungrateful by shaming him here in a foreign land. If they have a grievance, they first laid it at the foot of their family of origin, who would now ostensibly be expected to take the matter to the marriage go-between, also known as the person who helped contract the marriage. It is when all fails that the immediate extended family may be made privy. Recall that 78 women or the equivalent of 80 percent of the respondents stated not having family members here in North America, never mind laying their complaints before them. In this case, who are they going to complain to in a foreign land? Robert Wood Johnson Foundation (2009) buttresses this argument by declaring that:

Cultural values and practices are a significant influence on various aspects of intimate partner violence in immigrant and refugee communities. For example, some women come from cultural backgrounds, where men have near-absolute authority, and cannot imagine someone intervening on their behalf. Similarly, some types of arranged marriages involve uneven social and economic resources that make foreign-born women especially vulnerable to their partners' control (para.28).

The fear over washing the family's dirty linin in the public is exemplified by the comments made by the next respondent, whose pseudonym is Iribagiza. I met Iribagiza at a community event in the United States. She speaks English and French, so can I, which made the discussion, as painful as it was, comprehendible. I ascertained that she had a support person during the interview and after signing the required consent to have a support person of her choice present. She is Rwandan, one who came from a tightly regimented society and one organized in a pyramidal fashion, from the smallest district to the top tier of the government. The existence of Prefectures in Rwanda (Chemouni, 2014), ascertained the maintenance of a strong social control, especially by those in power or authority. She arrived in the United States during the mass murder that occurred in her country from April 7 to July 15, 1994 (BBC News, 2019).

Investigator: Hi Iribagiza (struggling to pronounce the name correctly). What happened, what's going on between you and your husband, if I may ask?

Iribagiza: (the name means glittering, glorious, shimmering). As you see me now, I am no longer what my name means. I am no longer glittering, glorious or shimmering...look at all the scars on my body from his brutality, "regarde moi" (look at me she said in French). I came from one trouble since the killings in my country and then here I am with my husband, who is supposed to protect me trying to kill me-sobbing loudly. He has been acting like the Interahamwe (a Rwandan youth wing accused of much of the genocide) in that nation.

Recalls Iribagiza, it started when I decided to return to school and he refused. He felt that I was going to begin making my own money and become independent and that drove him mad. He got upset over every little thing and beats me...il me bat terriblement...il menace de me tuer (he beats me terribly...he threatens to kill me). I think he may have small madness from what happened in our country in 1994, but he refuses to go for help. Me, am afraid of telling anyone...there is no one to go to and I'm scared because they will say that I am complaining about my husband. Je ne sais pas pourquoi il se comport comme ca (I don't know why he's behaving like this). I have to leave him or he is going to kill me (sobbing)...

On this account, refugee and immigrant women would never take their family matters to a stranger, professional or not. This is one of the reasons that cultural community members, refugee and immigrant women, especially the undocumented among them, fail to seek counseling because it is alien to their cultural ways of doing things (Kallivayalil, 2010). The next reason for the fall through the cracks is what I refer to as the "melting pot" syndrome as practiced in the United States. 


\subsection{Impact of the melting pot syndrome (United States)}

The Melting pot paradigm especially in societies such as the United States (Booth, 1998), may further exacerbate the discomfiture of the immigrant and refugee woman, who is also an IPV victim. In the United States, the pressure to assimilate-speak English, and act like everyone else may result in what Flores-Ortiz (1993) refers to as cultural freezing by the IPV victim. Cultural freezing occurs, when the immigrant or refugee woman fears and subconsciously resists the abrogation of her cultural values. As shown by the study, most of the IPV women victims are from cultural communities, where not only does patriarchy reign supreme, but also the concept of masculinity trumps all other social variables and roles assignments. The thrust of this new culture in the western world may be so corrosive that it forces them to "freeze." For reasons that are yet to be ascertained, new immigrant women tend to be more socially mobile than their spouses and husbands, a situation that is the polar opposite in their countries of origin.

Some researchers suggest that this may be owed to the newfound freedom. With this upward mobility, the women become apprehensive over their new and perceived power status and seek to re-enact or recreate their normal role expectations, with the male spouse at the apex of the family pecking order. This overarching desire to maintain her cultural practices by placing her spouse's supremacy, the family dynamics and stability over her own need and safety, translates into the IPV victim's reluctance to seek help or leave the abuse, a situation that promotes self-immolation in the final analysis (Crandall et al., 2005; Moracco et al., 2005; Murdaugh et al., 2004; Kantor et al., 1994).

\subsection{Residential status and locations of IPV victims}

Levitas (2006) argues that housing and accommodation location, residency in problem accumulation zones, low or diminished psychological well-being, as concomitants of poverty and deprivation, increase the probability that refugee and immigrant women will face victimization in the form of intimate partner abuse. Industrialized nations of the world often make accommodations for the gentrification of some areas, while they unwittingly leave the others to their own devices, therefore ghettoization (Gibbons et al., 2018). Those, normally of the majority population have the financial clout and, including access to financial instruments like loans and lines of credit to purchase property in this area, as Arbuckle \& Wthke (1999) argue. The balance of the undesirable areas become the "ghettos" that refugee and new immigrant women and their family often can afford and do reside by default, with the obvious higher outcomes for intimate and family violence. In this, dispensation, 68 women or 70 percent of the participants informed that they lived in subsidized city property. 29 women or 30 percent of the respondents reported living in rented apartments, located in problem accumulation areas of the city, also referred to as "ghettos." None neither owned nor resided in a singlefamily home or unit. Of course, it is clear that the forced choices of residency, especially those that are isolated have concomitants for access or the lack thereof to needed services, which is the next line of argument in this study.

\subsection{Access to services}

Occupying the lower socioeconomic strata easily translates to a by-default residency in problem accumulation and unsafe neighborhoods. These neighborhoods are frequently known to be saturated with drugs, alcohol and other malaises of society that are not overtly visible in the more affluent neighborhoods (Scheppers et al., 2006). These areas are often isolated, even when they are in the center of everything. This condition is largely due to a lack of knowledge by its residents about services that are available, when and if they actually are available. When such services are available, the women now have to deal with the attitudes of some of the service providers.

\subsection{Service providers' attitudes and paradigms}

The behaviors exhibited by service providers towards their refugee and immigrant clients are reflective of and a microcosm of the attitude of the general population towards immigrants in general, including, refugee and undocumented immigrant women population (Rana, 2012; Ingram et al., 2010; Scheppers et al., 2006). Gang et al. (2002) found that over 80 percent of negative behaviors towards immigrants and minorities in Europe and other places occur, due to the influence by the general population, including those with heightened nationalist fervors (O'Rourke \& Sinnott, 2006) on this attitude. For Gang et al. (2002), the older, the sicker, the less educated and less enlightened 
and the more disadvantaged the population is, the more negative attitude they display towards immigrants. This negative attitude is largely owed to the paranoia of disruption in cultural and social values, as well as fear, sometimes, of unfounded, displacement from jobs and positions (Hainmueller \& Hiscox, 2010) by the new arrivals. On the other hand, the younger, more educated population could care less; therefore, have generally favorable attitudes towards the new immigrant population. It is apparent that the younger, more educated population sees the new immigrants as adding premium to their labor market and other spheres of the environment, rather than fear as competition (Bauer et al., 2000). It is from this pool that service providers arrive to serve immigrants, refugees, among them women with IPV experiences, resulting in mixed outcomes and outright failures.

Ethnic minorities in general, but especially women refugees and immigrants often do not speak the language of their new host country (see the section on language and communication to glean the percentage of participants in this study that spoke English language in North America), for a number of reasons (Bauer et al., 2000). Some of the reasons include a lack of education (only 30 women participants or 31 percent of respondents spoke a smattering of English), in their home countries prior to migration. Contingently, learning a new language in their host country becomes even more compounding, owing to multiple competing priorities. In Quebec, Canada or France for instance, both of which overtly exhibit nationalist fervor, the majority's disdain for those who do not speak French is palpable and translates into the type of, often lackadaisical services they provide to such immigrants. According to Scheppers et al. (2006):

The relationship between an ethnic minority patient and a physician is essentially vertical due to social differentials forced by unevenness on linguistic, cognitive and institutional levels. This gulf separates patients and physicians and invariably benefits the physician more than the patient. Parents of ethnic minority childpatients experienced the communication with the physician of their children more negatively, when compared with their socially dominant counterparts. Differences in experience were associated with differences in understanding each other. The problem of ineffective communication caused by language difficulties often stays unsolved, leading to frustration and exasperation with patients feeling neglected and detached (p.339).

\section{Three major areas or levels that constitute barriers for immigrants \& refugees adaptation and quest for services}

Scheppers et al. (2006) have identified three major areas or levels that constitute barriers for immigrants, refugees and vulnerable populations, especially refugee and immigrant, including undocumented women, who are also victims of IPV. Since the scope of this study would not permit an exhaustive analysis of these barriers, attempt is made below to succinctly enunciate them, and hopefully bring some elucidation to the subject matter of access or the lack thereof to services on behalf of this population. I begin my argument at the Patient level.

\subsection{Patient level}

Barriers to accessing services are the determinants of age, gender, marital status, education, social class and living conditions. Others are socioeconomic status, income and financial status, life-style, availability of transportation and mobility. Additional to these are travel times, community enabling resources and duration of stay in the host country. Still others are family and social support, knowledge about physiology and disease, communication, local language skills, translation, perception and attitude towards health services and personnel, personal enabling resources-predicated on immigration rules and visa status (Scheppers et al., 2006). Many of these variables impinge upon the immigrant's ability to seek and retain much needed services. In this, IPV immigrant and refugee women fare worse.

\subsection{Provider level}

At the Provider level, we explore the role and characteristics of the Provider, communication style, parallel sets of beliefs and practices, religious beliefs and spirituality. Provider level also include medical procedures and practices, orientation on immediate complaint, program orientation and ethnic matching, provider skills, including behavior, and discrimination. Many providers are not culturally trained, therefore ill-equipped to provide appropriate services to immigrant and refugee women, a situation that is compounded when such women are victims of Intimate Partner 
Violence.

\subsection{System level}

The Systems level provides the prism for conceptualizing medical paradigm, including the western medical method and fixation on allopathy. In the west, homeopathy and naturopathy are variants of medicine that have as yet no discernible foothold in medicine and treatment, while allopathy is practiced to the exclusion of others (Fleming \& Gutknecht, 2010). Other barriers at the Systems level continue in the form of consumerist approaches, intake procedures, opening hours, length of consultations and treatment. Most of these paradigms may be completely alien to the IPV immigrant and refugee woman. Therefore, rather than assist them, may further add to their victimization experience (Scheppers et al., 2006).

\subsection{Other anti-immigrant variables that promote IPV among immigrant and refugee women}

In identifying the challenges to addressing intimate partner violence in immigrant and refugee communities, the informant interviews of the 97 women in this study confirmed many of the findings in the literature review. Among the challenges identified:

Language barriers in service providers.

Lack of familiarity among immigrants and refugees about their legal rights and the system designed to protect them.

Fear of the authorities and deportation.

Fear of losing their children to the authorities, in light of IPV being evaluated as child maltreatment due to the latters presence during the events

Social and economic isolation.

Lack of community awareness about Intimate Partner Violence.

Lack of cultural competency within the police department, the court system, health care providers and even the domestic violence system.

A political landscape characterized by anti-immigrant sentiment, which tends to render the refugee, immigrant and undocumented women community more guarded in dealing with the outside world.

So, what can we do about these gaps in services to the refugee, immigrant and undocumented IPV women population? The following arguments represent evidence-based and best practice approaches to dealing with IPV among this population. I advance a note of warning that the paradigm shifts here are not put forth as elixir to the issue of IPV among this and other populations, for the problem of IPV is much more convoluted than these few policy recommendations. However, these paradigm shifts present as better options to what services and protocols currently exist for the population.

\section{Paradigm shifts}

Let us now explore several pertinent and sustainable recommendations that we hope will attempt to deal with the cankerworm of not only domestic violence against women, but those that portend to deal with IPV against immigrant, refugee and undocumented women as the most vulnerable of this gendered population. To begin with, just like Suffrage was difficult to navigate by American women in the period prior to 1920 (Hansan, 2011), so was the enactment of any meaningful laws that considered violence against women as worthy of attracting opprobrium. We begin with the Violence Against Women Act timelines in the United States (VAW Office, 2000, 2005). The Violence Against Women Act timelines in the United States underscore the various concerted struggles and sacrifices that have been made to realize it. This is especially so in a world ruled by men, including me, among them chauvinists, misogynists and misogamists, who, by acts of commission or omission also constitute the largest perpetrators of violence against women. 


\subsection{The Violence Against Women Movement-Timelines: The United States IPV Policy as paradigm}

June 19, 1990-S. 2754, The then Senator Joseph Biden (Former Vice President to the Obama administration and since November 3, 2020, the President-elect of the United States of America) introduces the VAW bill in Congress, where it was read.

June 1991-On account of several incidents of abuse and bodily harm, which doctors were observing on battered women, the American Medical Association published and issued recommendations to physicians to inquire from women about abuse as a matter of routine.

January 21, 1993-Senator Joseph Biden re-introduces the bill and begins lobbying Congress to act to protect women.

\subsection{The Violence Against Women Act of September 13, 1994}

September 13, 1994-Under the Violent Crime Control and Law Enforcement Act, President Bill Clinton signs the Violence Against Women Act into law. VAWA of 1994 was enacted as a United States federal law (Title IV, sec. 4000140703 of the Violent Crime Control and Law Enforcement Act of 1994, H.R. 3355), signed as Pub.L. 103-322 (codified in part at 42 U.S.C. sections 13701 through 14040), (Sacco, 2015). The VAW law included an initial grant of \$1.6 billion for investigative and prosecutorial purposes. The caveat was that this law sunsets every 5 years if not reauthorized. For the first time in America's history, a Policy office of Violence Against Women and VAW Grants offices were established, now known as the Department of Justice, Office of Violence Against Women.

February 21, 1996-In its first month alone, The National Domestic Violence Hotline received gets 4,826 calls.

1999-The Violence Against Women Policy Office and the Violence Against Women Grants Office merge to become The Office of Violence Against Women.

October 28, 2000-Reauthorization by the President Clinton administration of the Violence Against Women Act, with a new addition involving the Trafficking Victims Protection Act, expanded to include Battered Immigrant women (Sacco, 2015).

August 2, 2003-The 1 millionth call registers at the VAW hotline

January 5, 2006-President George W. Bush signs The Violence Against Women and Department of Justice Reauthorization Act of 2005 into law. This reauthorization includes provisions on the use of DNA fingerprinting for Native American women, as well as on dating violence (Sacco, 2015).

April 28, 2009-Two million calls are made to and received by the VAW hotline

April 26, 2012-VAWA is reauthorized by Senate as S.1925 and expanded to accommodate battered undocumented immigrant women, LGBTQ+ community and Native Americans.

May 16, 2012-The House of Representatives agrees and reauthorized VAWA as HR 4970, but expunges the expanded measures that were adopted by the Senate. The expanded measures included advocacy clauses that protected the rights of undocumented (illegal) immigrant women, Native American women, the LGBTQ+ community and teen dating violence and the Trafficking Victims Protection Act.

December 31, 2012-The VAWA reauthorization runs into a stalemate, due to disagreements between the majority Parties-Republicans and Democrats, which precipitated its sun setting (for not being renewed by Congress after 5 years) for the first time since the enactment of the VAW Act in 1994.

\subsection{The Violence Against Women Act-reauthorization of March 7, 2013}

March 7, 2013-President Barack Obama signs into law S.47, the Violence Against Women Reauthorization Act of 2013, with new provisions that were initially expunged by the Lower House. This reauthorization addresses the rights of undocumented immigrant women and Native American women. In the case of Native American Women, VAWA 2013 created congressional authority for up to \$25 million as tribal grants in fiscal years 2014 to 2018 , which Congress was tardy initially in appropriating the funds. Nonetheless, Tribes were allowed to continue to apply for funding through the Department of Justice's Coordinated Tribal Assistance Solicitation (CTAS), designed to support VAWA implementation. Not only this, but it is possible for Tribes to seek additional federal funding sources. The other groups covered by the 
2013 VAWA reauthorization include the LGBTQ+ community and teen dating violence, as well as the Trafficking Victims Protection Act.

Gandy (2012) President and CEO, National Network to End Domestic Violence cites a new report by the Bureau of Justice Statistics that conclusively indicates that the Violence Against Women Act-VAWA and its reauthorizations since 1994 have proven to be effective in curbing IPV, especially those directed against women. The report suggests that there has been a 64 percent declination in nonfatal IPV between 1994-2010, since it became law in 1994. The report shows that IPV cases involving rape, sexual assault, aggravated assault, robbery, battery committed by a spouse, boyfriend, former spouse, etc. declined from its original 2.1 million cases in 1994 to a record low of 907,000 by the end of 2010. This welcome development speaks volumes, when compared to how women had for centuries, endured domestic abuse, once christened "domestic chastisement" and "private and family matter" (Stedman, 1917).

In light of men being the primary abusers of women and literally their usurpation of the power of life and death over women, prior to VAW, they did exactly how they pleased without accountability. The law enforcement agencies were rendered powerless, having neither the training nor legal authority to intervene. Women lived in fear for their lives and limbs because of their spouses, whose primary role was designed to love and protect them. Although a few women shelters existed, women were still stalked and sometimes gunned down at the shelters. Additionally, there was lacking a unified and system-wide intervention and coordination of safety programs. Each state was doing its own thing and perpetrators could simply leave one state, where they have abused a woman and be home free without being held accountable in another. No more, as VAW is now a federal offense and perpetrators now can run, but they have nowhere to hide.

July 2013-The hotline receives its three millionth call (US Congress: Violence Against Women Reauthorization Act, 2013).

Sponsored by Senator Patrick Leahy, the ranking Senate Democrat from Vermont, VAWA S.47 of 2013 (Violence Against Women Reauthorization Act, 2013) represents the most comprehensive civil rights protection act of the affected population but especially women since VAW bill was submitted by VP Biden as S. 2754 in 1990. The scope of this study precludes an in-depth analysis. However, we shall attempt, through this simplified translation of VAWA S.47 of 2013, to enunciate some of its most salient provisions in the following areas:

TITLE I-ENHANCING JUDICIAL AND LAW ENFORCEMENT TOOLS TO COMBAT VIOLENCE AGAINST WOMEN

TITLE II-IMPROVING SERVICES FOR VICTIMS OF DOMESTIC VIOLENCE, DATING VIOLENCE, SEXUAL ASSAULT, AND STALKING

TITLE III-SERVICES, PROTECTION, AND JUSTICE FOR YOUNG VICTIMS OF VIOLENCE

TITLE IV-VIOLENCE REDUCTION PRACTICES

TITLE V-STRENGTHENING THE HEALTHCARE SYSTEM'S RESPONSE TO DOMESTIC VIOLENCE, DATING VIOLENCE, SEXUAL ASSAULT, AND STALKING

TITLE VI-SAFE HOMES FOR VICTIMS OF DOMESTIC VIOLENCE, DATING VIOLENCE, SEXUAL ASSAULT, AND STALKING

TITLE VII-ECONOMIC SECURITY FOR VICTIMS OF VIOLENCE

TITLE VIII-PROTECTION OF BATTERED IMMIGRANTS

TITLE IX-SAFETY FOR INDIAN WOMEN

TITLE X-SAFER ACT

TITLE XI-OTHER MATTERS

(US Congress: Violence Against Women Reauthorization, 2013).

Post-2013 VAWA Reauthorization findings

The VAWA and its authorizations from 1993-2012 and the comprehensive S.47-Violence Against Women Reauthorization Act of 2013 by the 113th Congress (2013-2014) reauthorization and expansion of 2013 (US Congress: Violence Against Women Reauthorization, 2013) has made great strides in protecting women across the board. However, there are still several areas that women, particularly new immigrants and refugees remain highly at risk and vulnerable. In this caldron are the LGBTQ+ victims of domestic violence, who are, to say the least underserved and often, but futilely struggle to find justice. These women victims continue to face discrimination in housing and other areas, while the immigrants, refugees and undocumented abuse victim entities amongst them are too petrified to come 
forward for fear of deportation. The immigration process and procedure (Alaggia et al., 2009; Bauer et al., 2000), which entail resettlement and integration presents as one such case. Here, women are still highly vulnerable and the Violence Against Women Reauthorization Act-S.47 of 2013 alone does not even begin to dent the problems. I have taken some liberties to enunciate a number of paradigm shifts that we hope will assist in addressing some of the vulnerabilities of immigrant and refugee women (US Congress: Violence Against Women Reauthorization Act, 2013). See also (United Nations Entity for Gender Equality \& Empowerment, n.d.). The VAWA was thankfully reauthorized in 2019 as against 2011, when partisan politics derailed a reauthorization until 2013. This 2019 VAWA Reauthorization and its parameters is the subject of the next section of this discussion.

\subsection{The Violence Against Women Act-VAWA reauthorization of November 21, 2019}

In 2019 The VAWA was reauthorized as a five-year Violence Against Women's Act that reinforces existing law. This reauthorization also engages in making critically important improvements, contingent on reports and feedback from VAWA service providers and program beneficiaries (Hoyer, 2019). Owing to its comprehensiveness, only a listing of the contents of the 2019 Reauthorization is possible due to the scope of this study.

Enhances judicial and law enforcement tools and safeguards the Office on Violence Against Women at the Department of Justice

Expands STOP (Services, Training, Officers, Prosecutors) grants, adding further community resources that are attune to and appropriate to incidences of Intimate Partner Violence.

In the case of students, it addresses bullying, supports prevention education for students, and expands training for campus health centers.

Updates the SMART (Students Management Anger Resolution Together) Prevention Program adding the component that engages men and boys in preventing violence.

Supports early childhood programs training on domestic violence, sexual assault, stalking and dating violence.

Preserves and enhances housing protections for survivors of IPV.

Reauthorizes the National Resource Center on Workplace Responses, protects employee victims as survivors from having their appointments terminated, and protects survivors' eligibility for Unemployment Insurance.

Addresses "intimate partner" homicides by prohibiting ex-convicts of dating violence or misdemeanor stalking, or from possessing firearms by those subject to ex parte protective orders.

Protects Native American women by enhancing access by tribes to federal crime information databases and reaffirming tribal criminal jurisdiction over non-Indian perpetrators of domestic violence, sexual assault, dating violence, stalking, and trafficking for all federally recognized Indian tribes and Alaskan Natives (Hoyer, 2019).

Although it is heartening to know that the VAWA has received several reauthorizations since its enactment in 1994 and continuing to 2019, however, much is still desired to address the vulnerabilities of women, including especially immigrant, refugee and undocumented women. The following represent a few policy recommendations designed to enhance and consolidate the existing protections. It begins with gender specific immigration reforms and practices.

\subsection{The 2019 Violence Against Women Act-VAWA Reauthorization parameters}

In 2019 The VAWA was reauthorized as a five-year Violence Against Women's Act that reinforces existing law. This reauthorization also engages in making critically important improvements, contingent on reports and feedback from VAWA service providers and program beneficiaries (Hoyer, 2019). Owing to its comprehensiveness, only a listing of the contents of the 2019 Reauthorization is possible due to the scope of this study. They are as follows:

Enhances judicial and law enforcement tools and safeguards the Office on Violence Against Women at the Department of Justice

Expands STOP (Services, Training, Officers, Prosecutors) grants, adding further community resources that are attune to and appropriate to incidences of Intimate Partner Violence.

In the case of students, it addresses bullying, supports prevention education for students, and expands training for campus health centers.

Updates the SMART (Students Management Anger Resolution Together) Prevention Program adding the component that engages men and boys in preventing violence. 
Supports early childhood programs training on domestic violence, sexual assault, stalking and dating violence.

Preserves and enhances housing protections for survivors of IPV.

Reauthorizes the National Resource Center on Workplace Responses, protects employee victims as survivors from having their appointments terminated, and protects survivors' eligibility for Unemployment Insurance.

Addresses "intimate partner" homicides by prohibiting ex-convicts of dating violence or misdemeanor stalking, or from possessing firearms by those subject to ex parte protective orders.

Protects Native American women by enhancing access by tribes to federal crime information databases and reaffirming tribal criminal jurisdiction over non-Indian perpetrators of domestic violence, sexual assault, dating violence, stalking, and trafficking for all federally recognized Indian tribes and Alaskan Natives (Hoyer, 2019).

Although it is heartening to know that the VAWA has received several reauthorizations since its enactment in 1994 and continuing to 2019, however, much is still desired to address the vulnerabilities of women, including especially immigrant, refugee and undocumented women. The following represents a few policy recommendations designed to enhance and consolidate the existing protections. It begins with gender specific immigration reforms and practices.

\section{Comprehensive sustainable practices and recommendations to attenuate violence against women}

\subsection{Gender-specific, gender friendly immigration reform}

The current family-type immigration policy, which relies on the man as the head of the family, thereby subordinating everyone, including adult women is a patriarchal arrangement that has reached obsolescence and needs serious and urgent revision. In many cases, immigrant and refugee women's status depends on a male spouse's visa or citizenship of the host country. Rana (2012) paints the situation aptly:

A survivor's immigration status influences her access to legal protections, which in turn influences her risk for

domestic violence. Abusive partners often use survivors' immigration status to threaten them with deportation and to control them in various ways (p.2).

Rana's argument (See also Rana \& Marin, 2012) finds support in a study (Crandall et al., 2005) of 24 Russianspeaking immigrant women. The study found that male abusers successfully threatened their female spouses with deportation by deliberately declining to complete the required documents for their spouses. The men also declined to follow through with acquiring permanent residency or Green Cards on their behalf. Dutton et al. (2000) agree, but suggest further that the abuser's obsession with power and control is lent weight by the immigration procedures. These procedures provide carte blanche to citizens and legal residents' ultimate control over the filing of immigration papers on behalf of their foreign partners, who by default are always women. Thus, the women lack the social and economic wherewithal to pursue status independently of their abusive spouses, where this is the case. These women therefore are not authorized to seek or accept legal employment that would otherwise provide them the pecuniary resource to become independent. When this is the case, the dynamics of power and control, which is lop-sided in favor of the male spouse becomes seed money for domestic abuse often of the woman.

Under the Violence Against Women Act (Sacco, 2015; US Congress: VAWA Reauthorization, 2013) some female victims of intimate partner violence and abuse can self-petition for status. The caveat in this case is that this is only limited to spouses of US citizens and lawful permanent residents. Even then, with the successful petition, the woman receives only deferred action, which in and of itself is not a status. Additionally, there is a significant backlog in the family-type immigration process, including up to a one-year wait for employment authorization, the yearly renewal of work authorization and reentry constraint if they leave the host country for any reason. Worse still, most refugee and immigrant women are unaware and unable to navigate the systems. Recall that 57 percent of the respondents in this study barely attained Junior high school certification. They are unaware of their civil rights under the law, the systems processes or the need to leave paper trails or gather enough or any evidence to prove the occurrence and existence of abuse in their partnership (Ingram et al., 2010; Bhuyan et al., 2005; Crandall et al., 2005; Latta \& Goodman, 2005; Sullivan et al., 2005).

Matters are further exacerbated by the Department of Homeland Security's initiation of many local lawenforcement initiatives and partnerships that further victimize women. One of these is $287(\mathrm{~g})$ and Securities 
Communities Initiatives (US Immigration and Customs Enforcement (ICE), n.d.). These immigration initiatives and entities increase local law enforcement identification of undocumented immigrants, who are subsequently detained and prepared for removal. Although it is laudable to use these entities to rid the United States of criminals and undesirable elements, they are however counter-productive to the welfare of women, especially the refugee and undocumented migrant types. In many cases these women, who are frequently reported by angst-laden and vengeful spouses for this purpose, are arrested, detained and processed for removal, whereas the real issue is IPV perpetrated against the woman by the man. When this occurs, the woman is further victimized, while the perpetrator, who ought to face felony charges, walks. With this development, it is easier for the victim of domestic abuse to remain with the abuser rather than seek protection from the police and law enforcement agencies. An urgent review of this practice will mean that women victims of domestic abuse can be assisted to fast-track and regularize their status, while perpetrators can no longer find any lacuna for continuing their abuse, as well as can be swiftly held accountable.

\subsection{Providing culturally competent, culturally relevant services and practitioners}

In an increasingly global word, cultural competency on the part of systems, service providers and practitioners is a sine qua non. It is no longer a convenience, but a necessity if we are to be successful in integrating immigrants, especially women victims of IPV into the societies they find themselves. To achieve this, systems, advocates and practitioners must study and comprehend the dynamics of IPV. In addition, they must empower victims by engaging in behaviors and paradigm shifts that reflect the cultural and experiential lives of victims, who will now apply this newfound power to make informed decisions about their lives and those of their children. Providing culturally competent services must include a comprehension of the legal processes (Erez, 2002) that apply to, not only immigrants and refugees in general, but particularly, women as a vulnerable immigrant population. In line with the competency services, should be the provision of critical language interpretation and translation services, which is an invaluable protection and comprehension vehicle for the immigrant and refugee IPV victim. Translation and interpretation services for this population act to effectively communicate their experiences, promoting and enhancing not only the victim's immediate and future safety, but simultaneously building trust in the systems, service providers and practitioners. Show me a battered woman, who felt misunderstood because of language incompetency on the part of practitioners, and I will show you a woman who will not only be disinclined to return for services, irrespective of their situation, but also one who will soon become an IPV statistic.

\subsection{Provision of acute, on-going and comprehensive services}

Most refugees and immigrants leave their normal places of domicile rather hurriedly and before they are aware of their surroundings, they are already in a second or third country. This social, cultural and economic deracination accounts for their vulnerability to all sorts of misadventures including IPV, a fact that increases exponentially if they are gendered. In light of this, host countries must have plans to rapidly provide thorough, confidential and holistic succor to the women (Barr, 2009). These services include, but are not limited to temporary shelter, sustainable safety plans and orientation. Later, they will include education on the social and legal justice systems to assist them survive IPV. Others are assistance towards sustainable and permanent housing, balanced nutrition, legal assistance to navigate the systems, as well as mental health counseling and resources (Dutton et al., 2000).

Some of the banes of service systems as we have come to know them are the unnecessary overlaps and duplications that they are fraught with. Sometimes, and due to pork barrel politics (McElroy, 2013), existing programs are allowed to lie fallow, while new ones fitting the same definition and service components are unnecessarily designed and erected. To avoid this waste of taxpayers' resources, agencies, systems and practitioners that already assist and work with refugees should receive additional funding and resources. These resources should include cultural competency training-new and innovative paradigms and shifts in gender roles and expectations, including attitudes and behaviors of service providers and practitioners towards refugees and women in particular. These resources should all be designed to improve outcomes for this population. It is feasible that new programs are inevitable and developed for new communities, especially to increase access. However, effort should be made to liaise and collaborate with other existing successful programs, thereby increasing outreach, reducing hopeless duplications and promoting best practice methods across communities and localities. 


\subsection{Refugee and immigrant women's skills training and development}

Although many of the new immigrant and refugee women may already have skills, these may be in cultural and employment dissonance with the ones used in the host countries. To this extent, the provision of broad skills and life training may include language, computer skills, Internet use, job search skills, driving and transportation (Barr, 2009). The use of telephones, finances, etc., could become the elixir for employment and revenue generation, which in turn translate into an earning power and self-sufficiency for the IPV victim.

\subsection{Increase emphasis on prevention}

The problem with a host of ineffective programs, especially those existing for the benefit of immigrants and refugees are that they are mostly reactive rather than proactive. For immigrant and refugee women, the most important intervention is prevention, through engaging in community awareness initiatives. These initiatives will be designed to train community leaders among them for sustainability of purpose. For a preemptive strike to be effective, systems must engage in policy analysis and communication of the findings to policy makers, which stands to enhance informed policy changes prior to their enactment. Initiatives must be proactive because, policy changes become challenging to secure once they become law. This can be achieved through incorporating and allowing victims voices (Bhuyan et al., 2005) to share their experiences with the policy makers and the wider audience (Crandall et al., 2005). Additional to these is the need to engage in and raise awareness, as well as promote the practice of culturally relevant leadership activities and initiatives among all, but especially men who are mostly in charge, therefore control refugee and immigrant social structures.

\subsection{Extend VAWA IPV coverage \& service to same sex couples \& the LGBTQ+ population}

Intimate Partner Violence is the new epidemic (Shwayder, 2013) amongst the LGBTQ+ population, and not much is being said or done about it. Why? There is an erroneous assumption that intimate partner violence is a phenomenon that exists and prevalent among heterosexual couples only-a man and a woman. Russell-Salvin (2019) shares staggering statistics that show that in their lifetime 44 percent of lesbian women, 61 percent of bisexual women, 26 percent of gay men, 37 percent of bisexual men and nearly half of transgender people will be victims of rape, unprovoked attacks or stalked by an intimate partner. Matters are not helped by homophobism (McDonald \& Hasselfield, 1997), which saturates the policy-making process and arena. The practice of homophobism leads to foot-dragging or complete inaction on behalf of this originally closeted, but currently ever increasing population of fellow planet-dwelling humans.

The CDC in 2013 released a 2010 study findings on victimization by sexual orientation. In this report, it owned up to being clueless about the national prevalence of IPV, sexual violence, and stalking occurring in the LGBTQ+ population in the United States (The Centers for Disease Control and Prevention's (CDC) National Intimate Partner and Sexual Violence Survey (NISVS), 2010). Findings from this report showed that women bisexuals "attracted" much more significantly higher violent partners at 75 percent, compared to 46 percent for lesbians and 43 percent for heterosexual women. Conversely, the percentage for bisexual men was 47 percent, 40 percent for gay men and nearly half at 21 percent for heterosexual men.

To muddy the waters even further, The National Coalition of Anti-Violence Programs (2011) survey and subsequent statistics indicate that the LGBTQ+ homicide rates for the year outpaced (highest ever recorded) that for 2010, with 19 IPV homicides in the year under review. This is more than three times the six LGBTQ+ homicides that were reported in 2010. Of these, 63.2 percent or 12 participants of the IPV homicide victims were men, while 7 were women, with 2 identifying as transgendered. A cursory exploration of the homicide victims shows that a significant shift among genders in the 2010 report has occurred. Here, 66.7 percent of the LGBTQ+ homicide victims were identified as women.

The scope of this study precludes in-depth exploration of this demographic. Suffice it to say that despite the country-wide receipt by NCAVP program of 2,679 reports of IPV in 2012, and an increasing number of statistical data on IPV among this population, many of the member organizations were not providing the much needed services (National Coalition of Anti-Violence Programs (NCAVD) Report, 2011). They were not, and indeed continue to limit the number of files they can open and maintain due, to inadequate funding. One note of warning is that regardless of the inclination of American society's ethos to pretend that the LGBTQ+ population is either a fad or non-existent phenomenon, it is 
inevitably going to constitute one of the largest civil rights movement in the country and the world to boot. To this extent, the sooner policy makers "get with the program" by developing adequate funding mechanisms, the sooner society can begin to get a handle on the burgeoning rates of IPV and homicide rates among this population.

\subsection{Promote program evaluation, technique and research}

Program evaluation as a concept is derived from the need by managers, systems, service providers and individual practitioners to articulate the impact and value of their programs. They achieve this by asking formal and informal questions, consulting with partners and consumers, engaging in assessments and obtaining feedback, which they then apply to improve the program outcomes (Centers for Disease Control and Prevention, 2012). According to Scriven (as cited in Centers for Disease Control and Prevention, 2012), evaluation simply means "examination of the worth, merit, or significance of an object" (para.1).

To be clear, evaluation of program goes on all the time at both the formal and informal levels. Formal evaluation is however distinguishable from the informal type in that the formalized type is conducted contingent on a set of rules and guidelines. Succinctly put, it entails a systematic collection and collation of information and data concerning the activities, characteristics, and outcomes of that program. In this way, judgment calls can be made, which then lead to enhancing program effectiveness and outcomes. Pertinently, it also pursues the realization of informed decisions about a future program development (Patton, 1997). Rather than occur in a vacuum, program evaluation is the outcome of realworld events, especially constraints-mainly promote efficiency and reduce waste. Contingently, program evaluation is designed to be practical, feasible and in line with availability and management of resources, time and political dictates. The overarching variables are that evaluation must serve a useful purpose, in addition to meeting ethical standards, producing as close to an accurate finding (when controlling for margins of error) as possible and enhancing program outcomes. In tandem with program evaluation is research, which uncovers new techniques that are based on evidence and best practice modalities. In the case of IPV, especially among the population under review, research permits the unveiling of more and new information about its incidence in specific and designated communities. Effective research then identifies and promotes efficacious responses and approaches that stand to sustainably enhance victim safety and self-empowerment.

\section{Conclusion}

Intimate partner violence has been in existence since human history as an aberrant form of interaction, but especially the exercise of raw and unjust power (mostly by men) against those who are vulnerable, especially women (Jones, 2012). Having been in existence for as long as humans, does not provide it carte blanche authority to remain and continue its victimization of women. The case of refugee, displaced and undocumented immigrant women is particularly disturbing, but emits a compelling clarion call for sustainable solutions. This is for the fact that these hapless women are escaping mayhem in their normal domiciliary spaces and desire some right to succor. Be that as it may, those who are supposedly their spouses, partners, paramours and protection agencies become the gnomes that are threatening to devour them. IPV among this population is contingent on the same power imbalances that existed in their countries of origin, which have received expansion nod (by acts of commission or omission) even in the new societies that they are seeking refuge, by a male chauvinist society. For refugee and displaced women, the fact of their gender is already a "handicap" on a prima facie basis because the universality of acquiescence of violence against women, knows no continental shelf (Mackinnon, 2006). Violence Against Women exists everywhere and in every culture, race, religion, sexual orientation and creed. Whereas women endure harrowing experiences of IPV in their own countries and places of normal residence, that for refugees, displaced and undocumented women presents with hydra-headed challenges, including physical and emotional distress. This unpalatable experience is contingent upon the concept of deracination, language barriers, power and socioeconomic dispensation that is lop-sided against them. The coup de grace is presented by an immigration system that strangle-holds this population, owing to its policy-driven reliance on the "statused" abuser for the wellbeing of the woman victim. How paradoxical?

Commonsensically, there must be something wrong with the picture that condemns a refugee/displaced and undocumented woman to further emasculation by a violent male, just for the fact that the former is a new migrant, has 
limited language skills in the new society or does not possess a regularized status. In light of this, the authorization and reauthorization of VAW protocol up to 2019 in the United States for instance, is a welcome development in an increasingly violent world, especially those that continue to devalue women, but more especially, refugee women, who lack the language to communicate. Although there have been several reauthorizations in the United States of the VAWA up to 2019 for five years, there is a need to continue a vigorous review of areas related to gender-specific, gender friendly immigration reform.

Others include the funding and provision of culturally competent services and practitioners; the establishment and sustainable provision of acute, on-going and comprehensive services; promotion of skills training and development; the diminishment of an obsolete, reactive intervention model, in preference for an increased emphasis on prevention of mayhem against this population. The others are the engagement in vigorous program evaluation, technique and research to, not only inform best practice, but also promote our journey of conscience to equality. Finally, the issue of a burgeoning IPV prevalence among the LGBTQ+ population, calls for immediate policy pronouncement and action, since this population of fellow citizens and humans have nowhere else to go. Therefore, they must be extended the same rights and privileges of both citizenship of the nation and human race (Russell-Salvin, 2019). Where we fail, we shall be paying a rather handsome premium for our pretentious laxes now or in the very near future.

\section{References}

Alaggia, R., \& Maiter, S. (2006). Domestic violence and child abuse: Issues for immigrant and refugee families. In Ramona, Alaggia \& Cathy Vine (Eds.), Cruel But Not Unusual: Violence in Canadian Families (pp. 99-126). Wilfrid Laurier University Press.

Alaggia, R., Regehr, C., \& Rishchynski, G. (2009). Intimate partner violence and immigration laws in Canada: How far have we come? International Journal of Law and Psychiatry, 32(6), 335-341.

Arbuckle, J. L., \& Wothke, W. (1999). Amos 4.0 User's Guide. Spss/Smallwaters Corporation.

Asylum Aid. (2003). Refugee women and domestic violence. Country Studies. https://www.refworld.org/pdfid/ 478e3c680.pdf

Bachman, R. (2000) A comparison of annual incidence rates and contextual characteristics of intimate perpetrated violence against women from the national crime victimization survey (NCVS) and the national violence against women survey (NVAW). Violence Against Women, 6(8), 839-867.

Barr, B. M. (2009). Meeting the Needs of Immigrant and Refugee Victims of Intimate Partner Violence, by Providing Comprehensive, Confidential and Holistic Services. Robert Wood Johnson Foundation. http://www.rwjf.org/ reports/grr/063180.htm.

Barnett, O. W., Miller-Perrin, C. L., \& Perrin, R. D. (2011). Family violence across the lifespan: An introduction (3rd ed.). Sage Publications.

Bhuyan, R., Mell, M., Senturia, K., Sullivan, M., \& Shiu-Thornton S. (2005). Women must endure according to their Karma: Cambodian immigrant women talk about domestic violence. Journal of Interpersonal Violence, 20(8), 902921. https://doi.org/10.1177/0886260505277657.

Bauer, T., Lofstrom, M., \& Zimmermann, K. F. (2000). Immigration policy, assimilation of immigrants, and natives' sentiments towards immigrants: Evidence from 12 OECD countries. Swedish Economic Policy Review, 7(2), 1153.

BBC News. (2019). Rwanda Genocide: 100 days of slaughter. BBC News. https://www.bbc.com/news/world-africa26875506.

Booth, W. (1998). The myth of the melting pot-America's racial divide: One nation indivisible: Is it history? The Washington Post (pp. A1). http://www.washingtonpost.com/wp-srv/national/longterm/meltingpot/melt0222.htm

Centers for Disease Control-CDC. (2013). DGMQ stories: The long road to America-one refugee's experience. National Center for Emerging and Zoonotic Infectious Diseases. Division of Global Migration and Quarantine. http://www. cdc.gov/ncezid/dgmq/pdf/world-refugee_508.pdf

Centers for Disease Control-CDC. (2012). Introduction to program evaluation for public health programs: A self-study guide. CDE. http://www.cdc.gov/eval/guide/introduction/

Centers for Disease Control \& Prevention. (2012). Introduction to program evaluation for public health programs: A self-Study guide: What is program evaluation? Centers for Disease Control and Prevention. http://www.cdc.gov/ EVAL/guide/introduction/index.htm 
Centers for Disease Control-CDC. (2010). The national intimate partner \& sexual violence survey: 2010 findings on victimization by sexual orientation. CDC. National Center for Injury Prevention \& Control, Division of Violence Control. http://www.cdc.gov/violenceprevention/pdf/nisvs_sofindings.pdf

Chemouni, B. (2014). Explaining the design of the Rwandan decentralization: Elite vulnerability and the territorial repartition of power. Journal of East African Studies, 8(2), 246-262.

Cooper, A., \& Smith, E. L. (2011). Homicide trends in the United States, 1980-2010. Office of Justice Programs, Bureau of Justice Statistics, United States Department of Justice. http://www.bjs.gov/content/pub/pdf/htus8008.pdf

Crandall, M., Senturia, K., Sullivan, M., \& Shiu-Thornton, S. (2005). No way out: Russian speaking women's experiences with domestic violence. Journal of Interpersonal Violence, 20(8), 941-958.

Dobash, R. E., \& Dobash, R. P. (1977). Wives: The appropriate victims of marital violence. Victimology, 2(3-4), 426442.

Durkheim, E. (1893/1947). The division of labor in society. The Free Press.

Dutton, D. G (1998). The abusive personality: Violence and control in intimate relationships. The Guilford Press.

Dutton, M. A., Orloff, L., \& Hass, G. A. (2000). Characteristics of help seeking behaviors, resources, and service needs of battered immigrant latinas: Legal and policy implications. Georgetown Journal of Poverty and Law Policy, 7(2), 245-303.

Easteal, P. L. (1994). Addressing violence against women in the home: How far have we come? How far to go? Family Matters, 37, 86-93.

Erez, E. (2002). Domestic violence and the criminal justice system: An overview. Online Journal of Issues in Nursing, 7(1), 4. http://www.nursingworld.org/MainMenuCategories/ANAMarketplace/ANAPeriodicals/OJIN/ TableofContents/Volume72002/No1Jan2002/DomesticViolenceandCriminalJustice.html

Felson, R. (2002). Violence and gender reexamined. American Psychological Association.

Fleming, S. A., \& Gutknecht, N. C. (2010). Naturopathy and the primary care practice. Primary Care, 37(1), 119-136.

Flores-Ortiz, Y. (1993). La mujer y la violencia: A culturally based model for the understanding and treatment of domestic violence in chicana/latina communities. In N. Alarcon (Ed.). Third Woman Press.

Gandy, K. (2012). Intimate partner violence report proves VAWA works. National Network to End Domestic Violence. http://www.huffingtonpost.com/kim-gandy/violence-against-women-act_b 2237264.html

Gang, I. N., Rivera-Batiz, F. L., \& Yun, M-S. (2002). Economic strain, ethnic concentration and attitudes towards foreigners in the European Union. IZA Discussion Paper No. 578.

Gangoli, G. (2017). Understanding patriarchy, past and present. Journal of Gender-Based Violence, 1(1), $127-134$.

Gaspar, D. B., \& Hine, D. C. (1996). More than a chattel: Black women and slavery in the Americas. Indiana University Press.

Gibbons, J., Barton, M., \& Brault, E. (2018). Evaluating gentrification's relation to neighborhood and city health. PLoS ONE, 13(11), e0207432. https://doi.org/10.1371/journal.pone.0207432.

Greenfeld, L., Rand, M., Craven, D., Klaus, P. A., Perkins, C. A., Ringel, C., Warchol, G., Matson, C., \& Fox, J. A. (1998). Violence by intimates: Analysis of data on crimes by current or former spouse, boyfriends, and girlfriends (NCJ 167237). Department of Justice, Bureau of Justice Statistics.

Hainmueller, J., \& Hiscox, M. J. (2010). Attitudes toward highly skilled and low-skilled immigration: Evidence from a survey experiment. American Political Science Review, 104(1), 61-84.

Hammond, M., Howarth, J., \& Keat, R. (1991). Understanding phenomenology: A good introduction that is especially helpful for those coming from an analytical perspective. Blackwell.

Hansan, J. (2011). The women's suffrage movement. Social Welfare History Project. http://socialwelfare.library.vcu.edu/ woman-suffrage/woman-suffrage-movement/

Hemenway, D., Shinoda-Tagawa, T., \& Miller, M. (2002). Firearm availability and female homicide victimization rates among 25 populous high-income countries. Journal of the American Medical Women's Association, 57(2), $100-104$.

Hoyer, S. (2019). The bipartisan violence against women reauthorization act of 2019. Majority Leader, United States House of Representatives. https://www.majorityleader.gov/content/bipartisan-violence-against-womenreauthorization-act-2019.

Human Rights Watch. (2003). "We'll kill you if you cry": Sexual violence in the Sierra Leone conflict. Human Rights Watch, 15(1), A. https://www.hrw.org/report/2003/01/16/well-kill-you-if-you-cry/sexual-violence-sierra-leoneconflict

Husserl, E. (1962). Ideas: General introduction to pure phenomenology. Translated by W. R. Boyce Gibson. Collier, MacMillan.

Ingram, M., McClelland, D. J., Martin, J., Caballero, M. F., Mayorga, M. T., \& Gillespie, K. (2010). Experiences of immigrant women who self-petition under the violence against women act. Violence Against Women, 16(8), 858- 
880.

Jacobson, N. S., \& Gottman, J. M. (1998). When men batter women: New insights into ending abusive relationships. Simon and Schuster.

Jones, C. (2012). The married women's property acts (UK, 1870, 1882 and 1893). Historia. http://herstoria.com/?p=473.

Kallivayalil, D. (2010). Narratives of suffering of south asian immigrant survivors of domestic violence. Violence Against Women, 16(7), 789-811.

Kantor, G. K, Jasinski, J. L., \& Aldarondo, E. (1994). Sociocultural status and incidence of marital violence in hispanic families. Violence and Victims, 9(3), 207-222.

Kanuha, V. K. (2006). Exploring the construction of violence against women and children. NCJ 216951. US Department of Justice, National Institute of Justice.

Klein, E., Campbell, J, Soler, E., \& Ghez, M. (1997). Ending domestic violence: Changing public perceptions/halting the epidemic. SAGE Publications.

Kuerstein, A. K. (2003). Women and the law: Leaders, cases and documents (6th ed.). ABC-CLIO.

Latta, R. E., \& Goodman, L. A. (2005). Considering the interplay of cultural context and service provision in intimate partner violence. The case of haitian immigrant women. Violence Against Women, 11(11), 1441-1464.

Levitas, R. (2006). The concept and measurement of social exclusion. In C. Pantazis, D. Gordon, \& R. Levitas (Eds.), Poverty and social exclusion in Britain: The Millennium Survey (pp.123-160). The Policy Press.

Mackinnon, C. A. (2006). Are women human?: And other international dialogue. Belknap Press of Harvard University Press.

McCAll, G. J., \& Shields, N. M. (1986). Social and structural factors in family violence. In M. Lystad (Ed.), Violence in the home (pp. 98-123). Interdisciplinary Perspectives. Brunner/Mazel Inc.

McDonald, N., \& Hasselfield, G. (1997). Racism, sexism, homophobism: Managing harassment in the workplace (2nd Ed.). Cross Cultural Communications International, Inc.

McElroy, W. (2013). Pork-Barrel spending: The history of lipsticking pigs. The Future of Freedom Foundation. http:// fff.org/explore-freedom/article/pork-barrel-spending-the-history-of-lipsticking-pigs/

Merleau-Ponty, M. (1942). La Structure du comportement. PUF.

Moracco, K. E., Hilton, A., Hodges, K. G., \& Frasier, P. Y. (2005). Knowledge and attitudes about intimate partner violence among immigrant latinos in rural North Carolina. Violence Against Women, 11(3), 337-352.

Moran, D. (2000). Introduction to phenomenology: A comprehensive introduction to the different figures in the phenomenological tradition. Routledge.

Morash, M., Bui, H., Zhang, Y., \& Holtfreter, K. (2007). Risk factors for abusive relationships: A study of Vietnamese American immigrant women. Violence Against Women, 13(7), 653-675.

Murdaugh, C., Hunt, S., Sowell, R., \& Santana, I. (2004). Domestic violence in hispanics in the southeastern united states: A survey and needs analysis. Journal of Family Violence, 19(2), 107-116.

National Association of Social Workers. (2001). NASW standards for cultural competence in social work practice. author. NASW.

National Coalition of Anti-Violence Programs Report. (2011). Lesbian, gay, bisexual, transgender, queer and HIVaffected intimate partner violence. New York City Anti-Violence Project. http:/www.avp.org/storage/documents/ Reports/2011_NCAVP_IPV_Report.pdf

Nayak, M. B., Byrne, C. A., Martin, M. K., \& Abraham, A. G. (2003). Attitudes towards violence against women: A cross-nation study. Sex Roles, 49(7-8), 333-342.

Ogbuagu, B. C. (2012). Domestic conflicts and marital violence in diasporic Nigerian families: Is it time for a paradigm shift in cultural ways of thinking and acting? Journal of Alternative Perspectives in the Social Sciences, 5(1), 1-27.

O'Rourke, K. H. \& Sinnott, R. (2006). The determinants of individual attitudes towards immigration. European Journal of Political Economy, 22(4), 838-861.

Pan, A., Daley, S., Rivera, L. M., Williams, K., Lingle, D., \& Reznik, V. (2006). Understanding the role of culture in domestic violence: The Ahimsa project for safe families. Journal of Immigrant and Minority Health, 8(1), 35-43.

Patton, M. Q. (1997). Utilization-focused evaluation: The new century text (3rd ed.). Sage.

Rana, S. (2012). Addressing domestic violence in immigrant communities: Critical issues for culturally competent services. VAWnet, a project of the National Resource Center on Domestic Violence.

Rana, S., \& Marin, L. (2012). Addressing domestic violence in immigrant communities: Critical issues for culturally competent services. National Online Resource Center on Violence Against Women. http://www.vawnet.org/Assoc Files_VAWnet/AR_DVImmigrantComm.pdf

Rand, M. R. (1997). Violence-related injuries treated in hospital emergency departments. US Department of Justice, Bureau of Justice Statistics. http://www.bjs.gov/content/pub/pdf/VRITHED.PDF. 
Rennison, C. M. (2003). Intimate partner violence, 1993-2001. US Department of Justice, Office of Justice Programs, Bureau of Justice Statistics Special Report, NCJ 197838. http://bjs.ojp.usdoj.gov/content/pub/pdf/ipv01.pdf

Refugee Women's Alliance-ReWa. (n.d.). Domestic violence: Domestic violence and sexual assault. Refugee women's alliance-reWa. http://www.rewa.org/index.php?q=node/8

Ridgeway, C. (2014). Why status matters for inequality. American Sociological Review, 79(1), 11-16.

Ridgeway, C., \& Correll, S. (2004). Unpacking the gender system: A theoretical perspective on gender beliefs and social relations. Gender \& Society, 18(4), 510-531.

Robert Wood Johnson Foundation. (2009). Intimate partner violence in \& immigrant and refugee communities: challenges, promising practices and recommendations. Robert Wood Johnson Foundation. https://www. futureswithoutviolence.org/userfiles/file/ImmigrantWomen/IPV_Report_March_2009.pdf

Rothman, J. C. (2008). Cultural competence in process and practice. Building Bridges. Pearson Education.

Russell-Salvin, T. (2019). Opinion: For our LGBT community, we need a better violence against women act. California Health Report. https://www.calhealthreport.org/2019/06/10/for-our-lgbt-community-we-need-a-better-violenceagainst-women-act/

Sacco, L. N. (2015). The violence against women act: Overview, legislation, and federal funding. Congressional Research Service. https://www.hsdl.org/?view\&did=766526.

Scheppers, E., van Dongen, E., Dekker, J., Geertzen, J., \& Dekker, J. (2006). Potential barriers to the use of health services among ethnic minorities: A Review. Family Practice, 23(3), 325-348.

Shirwadkar, S. (2004). Canadian domestic violence policy and Indian immigrant women. Violence Against Women, $10(8), 860-879$.

Shwayder, M. (2013). A same-sex domestic violence epidemic is salient. The Atlantic. http://www.theatlantic.com/ health/archive/2013/11/a-same-sex-domestic-violence-epidemic-is-silent/281131/

Sokoloff, N., \& Dupont, I. (2005). Domestic violence at the intersections of race, class, and gender: Challenges and contributions to understanding violence against marginalized women in diverse communities. Violence Against Women, 11(1), 38-64.

Sokolowski, R. (2000). Introduction to phenomenology: A thematic introduction to a number of phenomenological (mainly Husserlian) concepts. Cambridge University Press.

Sorenson, S. B. (2006). Judgments about intimate partner violence: A statewide survey about immigrants. Public Health Reports, 121(4), 445-452.

Stedman, B. (1917). Right of husband to chastise wife. The Virginia Law Register, New Series, 3(4), 241-248. http:// www.jstor.org/stable/1106112?seq=1\#page_scan_tab_contents

Straus, M. A. (2005). Women's violence towards men is a serious social problem. In D. R. Loseke, R. J. Gelles, \& M. M. Cavanaugh (Eds.), Current controversies on family violence (2nd ed.). (pp. 55-77). Sage Publications.

Sullivan, M., Senturia, K., Negash, T., Shiu-Thornton, S., \& Giday, B. (2005). For us it is like living in the dark: Ethiopian women's experiences with domestic violence. Journal of Interpersonal Violence, 20(8), 922-940.

Tong, R. (1989). Women, sex, and the law (new feminist perspectives). Rowman and Littlefield Publishers.

United Nations Entity for Gender Equality \& Empowerment. (n.d.). Timeline of policy commitments \& international agreement. Virtual Knowledge Centre to End Violence Against Women \& Girls. United Nations Entity for Gender Equality \& Empowerment. http://www.endvawnow.org/en/articles/302-timeline-of-policy-commitments-andinternational-agreements-.html

United States Census Bureau. (2008). American community survey. United States Census Bureau. http://factfinder. census.gov/servlet/STTable?_bm=y\&-geo_id=01000US\&-qr_name=ACS_2008_3YR_G00_S0501\&-ds_name= ACS_2008_3YR_G00_\&-redoLog=false

United States Congress (2013). Text of the violence against women reauthorization act of 2013. United States Congress. https://www.govtrack.us/congress/bills/113/s47/text

United States Immigration and Customs Enforcement-ICE. (n.d.). Delegation of Immigration Authority Section 287(g) Immigration and Nationality Act. The Department of Homeland Security. http://www.ice.gov/factsheets/287g.

Violence Against Women Office (2000, 2005). The violence against women act of 2000, 2005 (VAWA, 2000, 2005). National Network to End Domestic Violence. http://www.ojp.usdoj.gov/vawo/laws/vawa_summary2htm

Wenger, J. R. (1992). Chattel or person?: The status of women in mishnah. Oxford University Press.

Womensafe. (n.d.). Overview of historical laws that supported domestic violence. Womensafe. http://www.womensafe. net/dv/dvlaws.html

Yllo, K. A. (2005). Through a feminist lens: Gender, diversity and biolence. In D. R. Loseke, R. J. Gelles, \& M. M. Cavanaugh (Eds.), Current Controversies on Family Violence (2nd ed.), (pp. 19-34). Sage.

Yoshihama, M. (2008). Literature on intimate partner violence in immigrant and refugee communities: Review and 
recommendations. In M. Runner, M. Yoshihama, \& S. Novick (Eds.), Intimate Partner Violence in Immigrant and Refugee Communities: Challenges, Promising Practices, and Recommendations (pp. 34-64). Family Violence Prevention Fund/Robert Wood Johnston Foundation. 